\title{
Análise Experimental do Comportamento e Sociedade: Um Novo Foco de Estudo
}

\author{
João Claudio Todorov ${ }^{1}$ \\ Universidade Católica de Goiás \\ Maisa Moreira \\ Universidade de Brasilia
}

\begin{abstract}
Resumo
O estudo do comportamento em sociedades foi relegado por quase 50 anos, apesar das reiteradas propostas de Skinner considerando sua importância. No ano de 1980, Sigrid Glenn criou o conceito de metacontingência que contribui como uma importante ferramenta para a descrição e análise do comportamento social. Neste artigo são apresentados alguns estudos envolvendo metacontingências e discute-se o papel do analista do comportamento no desenvolvimento de temas que abordam questões sociais, incluindo análise e modificação de práticas culturais.

Palavras-chave: Análise do comportamento; metacontingências; práticas culturais; sociedades; seleção por conseqüências.
\end{abstract}

Experimental Analysis of Behavior and Society: A New Field of Investigation

\begin{abstract}
Although there are many citations where Skinner writes about the importance of the study of cultural practices in behavior analysis, these studies were forgotten for almost fifty years. Working in this plan Sigrid Glenn has created the concept of metacontingency, a great contribution as a tool in the description and analysis of social behavior. Some metacontingency studies are presented in this paper and the behavior analyst's function in social issues is discussed, including analysis and modification of cultural practices.

Keywords: Behavior analysis; cultural practices; metacontingencies; society; selection by consequences.
\end{abstract}

Tragédias como a ocorrida em 11 de setembro de 2001, nos Estados Unidos, que resultou na morte de mais de 3000 pessoas e em posterior ataque dos Estados Unidos ao Afeganistão (entre milhares de outras tragédias que ocorrem todos os dias em nossos países, incluindo a atual invasão do Iraque) nos lembram que várias das nossas práticas culturais trazem prejuízos às vidas de todos. Apesar dos grandes progressos técnicos e científicos, não há suficiente preocupação sobre o gasto dos recursos naturais ou com a excessiva poluição das águas e do ar, e menos ainda mecanismos de controle do uso da violência, seja por pessoas, por organizações ou por países. Estas preocupações têm sido temas das ciências sociais, e com poucas exceções, a análise do comportamento não as tem abordado, apesar de ter considerável potencial para servir à nossa cultura no aumento das chances de sobrevivência, ou ao menos tornar mais compreensível os processos e as variáveis que determinam as direções atuais.

Este potencial, porém, tem sido pouco utilizado. Esta escassa exploração do potencial da análise do comportamento, no estudo social acontece apesar das contribuições de B. F. Skinner sobre a análise social e cultural como um componente fundamental do behaviorismo radical (Malagodi, 1986). Muitos trabalhos teóricos de Skinner (1953, 1955a,

${ }^{1}$ Endereço para correspondência: SHIN, QI 1, Cj. 9, Casa 11, 71505 090, Brasília, DF. 1955b, 1956, 1957, 1961, 1964,1968a, 1968b, 1969, 1972,1974, 1978) têm em sua compreensão uma nova visão de mundo (Michael, 1980; Todorov, 1982) que integra filosofia, ciência e princípios do comportamento dentro de uma teoria epistemológica consistente e geral do comportamento humano. O maior componente desta visão de mundo está na extensão de princípios comportamentais para a análise de processos sociais e culturais. Em "Ciência e Comportamento Humano" Skinner (1953) dedicou as três últimas seções para discutir extensivamente assuntos sobre a natureza, evolução, sobrevivência, valores e planejamento cultural.

Nesse sentido, a visão de mundo de Skinner implica em uma ciência do comportamento que estuda regras que descrevem as relações de controle entre contingências ambientais e comportamentos. Quando os membros atuantes da sociedade entram em contato com essas regras e as seguem, repertórios de solução de problemas são selecionados e mantidos por contingências de reforçamento existentes na cultura. Apesar deste tema ser importante para muitos, houve poucos estudos nos últimos 20 anos. A ciência do comportamento tem se dedicado a resolver problemas principalmente de indivíduos, ainda que em organizações ou instituições, muitas vezes vítimas de um mau planejamento cultural, mas sem um instrumental teórico explícito que se aplicasse ao comportamento de grupos sociais.

Glenn considerou importante esta interdisciplinaridade à medida que estudar sociedades e práticas culturais tendo 
como instrumento a contingência tríplice (Skinner, 1953; Souza, 1999; Todorov, 1985) pode não significar êxito total pois corremos o risco de reduzir a análise a um ponto que não mostra como se deu a evolução e a manutenção da prática em estudo. O nível comportamental da análise científica considera o organismo a base a partir da qual as relações funcionais entre o comportamento e os eventos ambientais são experimentalmente examinados (Glenn, 1988). Já na análise cultural o comportamento do indivíduo é a base a partir da qual práticas culturais emergem e o estudo das relações funcionais ocorre em outro nível.

Seleção em nível comportamental e seleção em nível cultural podem ser facilmente confundidos pois os dois envolvem relações entre eventos comportamentais e resultam em mudanças no ambiente. Conseqüências culturais, no entanto, não selecionam comportamentos individuais, selecionam relações entre contingências comportamentais, compreendendo as práticas culturais. O comportamento de um indivíduo específico tem pouco efeito nas conseqüências culturais.

\section{Metacontingências}

Para estudos do comportamento humano em nível social, uma importante unidade de análise usada é a metacontingência. Esta é uma unidade que descreve as relações funcionais entre classes de operantes, cada classe associada a uma contingência tríplice diferente, e uma conseqüência comum a longo prazo, comum a todos os operantes na metacontingência. Os comportamentos operantes dos membros do grupo formam um conjunto de ações coordenadas, geralmente chamado de prática cultural, que se relaciona a um ambiente comum aos membros. Práticas culturais envolvem o comportamento operante de grupos de pessoas que compõem a sociedade.

Metacontingências são relações contingentes entre práticas culturais e suas conseqüências. São relações funcionais em nível de análise cultural, cuja existência deriva mas não é equivalente a contingências comportamentais (Glenn, 1991). Uma metacontingência não é um arranjo de contingências individuais de diferentes pessoas. Ela consiste em contingências individuais interligadas, entrelaçadas, em que todas elas juntas produzem um mesmo resultado a longo prazo. O conceito de metacontingência nos permite efetivamente considerar o comportamento de grandes grupos de indivíduos em certas situações. Isso pode ser exemplificado pelos vários comportamentos envolvidos na redução da poluição do ar (Glenn, 1986).

Metacontingências envolvem essencialmente contingências socialmente determinadas. O elo de união de comportamentos individuais em uma metacontingência é a conseqüência a longo prazo que afeta toda a sociedade. São essas conseqüências que ligam as ações do dia-a-dia de diferentes pessoas e que podem ser controladas pelas regras da sociedade como, por exemplo, a Constituição (Todorov, 1987). Uma metacontingência existe se o objeto de análise for uma prática cultural de um grupo de indivíduos, se as conseqüências desta pratica, para o grupo, e se seus antecedentes puderem ser identificados (Glenn, 1986). No estudo das contingências sociais usando a unidade de análise metacontingência, há uma distinção entre contingências de reforçamento (relações de contingências entre uma classe de respostas e uma conseqüência comum) e metacontingências (relações de contingência entre uma classe de operantes e uma conseqüência cultural e comum a longo prazo).

No processo cultural existem metacontingências cerimoniais e tecnológicas, segundo Glenn (1986), aproveitando conceitos de Veblen (1899/1965). A Família, a Igreja e o Estado usam as metacontingências cerimoniais para garantir a manutenção do status quo da sociedade. Este controle cerimonial não é necessariamente nocivo ao indivíduo e à sociedade, mas é insensível às possibilidades de inovações de mudanças sociais construtivas (Todorov, 1987). O controle cerimonial pode ser exemplificado pela afirmativa: "Faça isso porque eu disse!" (Glenn, 1986). Este controle, apesar de garantir a ordem pela Família, Igreja e Estado, não incentiva a experimentação e adaptação desses comportamentos às mudanças sociais.

As metacontingências tecnológicas propõem um trabalho de determinação de regras específicas, de providenciar conseqüências imediatas para a observância dessas regras, e de avaliação dessas regras e das conseqüências (Todorov, 1987). O controle tecnológico pode ser exemplificado pela afirmativa: Faça isso porque resultará numa melhoria das condições sanitárias e conseqüentemente na melhoria da saúde (Glenn, 1986). Porém, mesmo as metacontingências tecnológicas após mudanças culturais podem posteriormente se tornar metacontingências cerimoniais cerceando nova evolução cultural. Por isso a avaliação das regras sociais deve ser um processo contínuo.

Sociedades se comportam governadas por metacontingências. Estas metacontingências podem ser definidas nos códigos e leis dos países. Em Estados democráticos de direito, como o Brasil, as metacontingências que controlam a sociedade são deliberadas democraticamente por um Congresso eleito pela maioria da população. Alguns exemplos são: a Constituição, o Código Penal, o Código Civil e o Estatuto da Criança e do Adolescente. Todos estes códigos de comportamento possuem metacontingências cerimoniais e tecnológicas. E pelos seus resultados no controle do comportamento podemos predizer que sua grande maioria é cerimonial. 
A idéia de planejamento cultural (Skinner, 1953) vai ao encontro das metacontingências tecnológicas, no sentido de procurar sempre estabelecer situações sociais deliberadas e que sigam também uma evolução cultural, acompanhando as mudanças que o ambiente sofre. As práticas culturais devem sofrer uma seleção natural para que continuem funcionais. A disfuncionalidade das práticas culturais, devido à inobservância das mesmas, pode ser constatada atualmente na questão das regras e da estrutura da família. A estrutura não é mais a mesma, pois o ambiente mudou. Não há mais lugar para a família patriarcal nesses dias em que o capitalismo demanda o poder aquisitivo e impulsiona os indivíduos ao consumismo. A família teve que se adequar a esta necessidade criada, transformando seus membros em força de trabalho ativa.

Concluindo, entendemos que o conceito de metacontingência amplia o campo de estudo da análise do comportamento. Ele resgata a preocupação de Skinner sobre planejamento cultural, já muito discutida em "Ciência e Comportamento Humano". O desenvolvimento do conceito de metacontingência mostra a importância da realização da pesquisa básica, mas enfatiza o valor dos resultados desta pesquisa no estudo social.

\section{Estudos sobre Metacontingências}

Todorov analisou a Constituição do Brasil sob o ponto de vista do conceito de metacontingência (Todorov, 1987). A Constituição de qualquer país traz, bem ou mal formuladas, metacontingências cerimoniais e tecnológicas. A Constituição outorgada pela Junta Militar em 1969 tem metacontingências relacionadas principalmente ao processo cultural cerimonial. Mas mesmo a Constituição de 1969 prevê a possibilidade de metacontingências relacionadas ao processo cultural tecnológico, ao prever emendas desde que aprovadas por dois terços do congresso.

Todorov (1987) se preocupou com o momento de revisão da Constituição de 1988 e considerou várias reflexões sobre as metacontingências cerimoniais e tecnológicas da Constituição. Dentre estes pontos de reflexão estão as perguntas: uma vez especificada a metacontingência, como garantir a especificação das novas regras a serem apreendidas por todos e que afetará o comportamento de cada um? Todorov argumenta que na revisão da Constituição (o trabalho foi escrito e publicado durante a Constituinte, antes da aprovação da Constituição de 1988) os constituintes deveriam se preocupar em não escrever uma Constituição extremamente cerimonial, frustrando as expectativas da população e esfacelando o amplo acordo político que sustentou a transição para a democracia, e nem extremamente tecnológica, com termos puramente abstratos como "a educação é um direito de todos e um dever do Estado", que não apontam os caminhos para a efetivação da idéia.

Lamal e Greenspoon (1992) descrevem uma metacontingência que controla a maioria dos comportamentos dos membros do Congresso dos EUA: a metacontingência da reeleição. Há um paradoxo entre os deputados e senadores: apesar de serem consistentemente reeleitos as pesquisas mostram que os eleitores que os elegem têm pouca estima por eles. Os padrões de votação dos membros do congresso podem, em muitas vezes, ser acuradamente previstos porque o seu comportamento de votar é positivamente e negativamente reforçado por grupos organizados (com interesses especiais) que pagam, dão apoio financeiro para que votem em causas que são benéficas a esses grupos. Assim, não é surpreendente que o comportamento de votar as leis seja consistente com o ponto de vista de grupos organizados.

O controle de grupos organizados sobre o voto dos deputados e senadores é relacionado em grande parte ao financiamento das campanhas eleitorais. Este controle tem crescido cada vez mais nos últimos 15 anos. A emergência e proliferação dos comitês políticos de ação tem um profundo efeito na contribuição das campanhas. Aqueles que votam nos candidatos (pela boa propaganda eleitoral) e os grupos organizados são sem dúvidas fontes de reforçamento deles. Algumas vezes os comitês políticos funcionam como operações estabelecedoras (Michael, 1982, 2000). Semelhantes aos comitês de ação política são os lobistas. Nos EUA lobistas têm adquirido considerável controle sobre deputados e senadores porque têm comando sobre a distribuição do dinheiro, especialmente em fundos de campanha, e porque estão freqüentemente relacionados aos comitês de ação política.

Um estudioso do Congresso americano descreveu três categorias de comportamento verbal dos congressistas, deputados e senadores: fazem propaganda, pedem verbas $\mathrm{e}$ tomam posições. Fazer propaganda envolve em sua grande parte tornar reconhecido popularmente seu nome, sendo a mídia, especialmente a televisão, uma importante fonte de controle em massa dos congressistas. A categoria de tomar posição significa fazer uma declaração em público que interesse aos constituintes e aos grupos organizados. A categoria de pedir verba consiste em fazer com que o governo providencie reforçadores aos constituintes, ou ao menos convencer os constituintes que é ele o responsável pelo que é feito no interesse deles.

Alguns membros do Câmara e do Senado, que são raros, responsabilizam-se por legislações que levam anos para serem aprovadas. Eles geralmente têm poucos votos e se engajam em temas controversos. Apesar disso continuam sendo reeleitos. Mas o que os reforça é fazer um bom trabalho aos 
constituintes, o qual chega ao conhecimento dos eleitores pela repercussão na imprensa.

A partir desta análise Lamal e Greenspoon (1992) percebem um fenômeno transcultural que serve de estrutura para a análise do comportamento de sociedades e práticas culturais. Um dos fenômenos é o estabelecimento e a manutenção de contingências que favorecem indivíduos ou grupos mas entram em conflito com o bem-estar da cultura. É o poder do reforçamento imediato do comportamento dos deputados e senadores que tem efeitos desastrosos para a sociedade a longo prazo, efeitos geralmente ignorados pela maioria do eleitorado.

A propaganda da campanha política do Presidente George Bush (pai do atual Presidente George W. Bush) alterou, para Laitinen e Rakos (1997), o controle da cadeia de comportamentos dos cidadãos que era controlada por reforçamento negativo passando a ser controlada por reforçamento positivo. Operações estabelecedoras (Michael, 1982, 1983, 2000) foram manipuladas para tornar o Iraque e Hussein estímulos aversivos e regras introduziram contingências aversivas: agressões espontâneas devem ser feitas contra eles para preservar a liberdade e a equidade. Isto estimulou uma concordância consensual "para fazer algo". Este "algo" passou para a história como a Guerra do Golfo. A solidariedade patriótica foi reforçada pelo reconhecimento de que ações não militares desempenhavam um papel importante contra o perigo. Contudo, concorrentemente, o estímulo aversivo da organização e preparação de tropas para o combate foi introduzido muito gradativamente para evitar respostas discordantes ou de esquiva da população. Posteriormente a organização das tropas militares cresceu imensamente mas sempre acompanhada por estimulação positiva como se esta ação fosse parte de esforços diplomáticos ou de aliança de vários países. Quando a guerra começou, a ação militar era um estímulo positivo e a guerra tinha como conseqüência reforçamento positivo e não negativo. Reforçamento positivo era assegurado ao não divulgar as conseqüências negativas da guerra e ao apresentar apenas as realizações tecnológicas e o sucesso das conquistas. Propaganda militar através da mídia de massa transformou a Guerra do Golfo em um grande entretenimento, ao qual os cidadãos respondiam com "entusiasmo patriótico". Os americanos aprenderam uma lição da experiência no Vietnam: para ganhar e manter o apoio à guerra na era da comunicação em massa, o controle de estímulos deve ser manipulado precisamente, o reforçamento positivo deve ser disseminado num grande esquema de difusão, considerando as metacontingências interrelacionadas que operam nos conglomerados de mídia (Leitinen \& Rakos, 1997).

\section{Conclusão}

Estes estudos sobre metacontingências fazem parte de uma pequena amostra do trabalho que os analistas do comportamento começam a fazer em nível social. Os trabalhos são importantes, mas é um campo de estudos que está apenas começando. Ainda são apenas estudos descritivos, e só com o aperfeiçoamento destes poderemos efetivar estudos sociais relevantes, aproveitando a oportunidade oferecida por verdadeiros experimentos naturais em andamento. Lembrando Charles Darwin, a predição e o controle não terão sucesso se o fenômeno a ser previsto e controlado não for adequadamente descrito e para isso nosso mais novo instrumento para o estudo é a metacontingência. A volta do Iraque ao centro do interesse da política externa dos Estados Unidos não deixa de ser uma excelente ocasião para conferir a análise funcional efetuada por Leitinen e Rakos (1997).

\section{Referências}

Glenn, S. S. (1986). Metacontingencies in Walden Two. Behavior Analysis and Social Action, 5, 2-8.

Glenn, S. S. (1988). Contingencies and metacontingencies: Toward a synthesis of behavior analysis and cultural materialism. The Behavior Analyst, 11, 161-179.

Glenn, S. S. (1991). Contingencies and metacontingencies: Relations among behavioral, cultural, and biological evolution. Em P. A. Lamal (Orgs), Behavioral analysis of societies and cultural practices (pp. 39-73). Washington, DC: Hemisphere.

Lamal, P. A. \& Greenspoon, J. (1992). Congressional metacontingencies. Behavior and Social Issues, 2, 71-81.

Malagodi, E. F. (1986). On radicalizing behaviorism: A call for cultural analysis. The Behavior Analyst, 9, 1-17.

Michael, J. (1980). Flight from behavior analysis. The Behavior Analyst, 3, 1-22.

Michael, J. (1982). Distinguishing between discriminative and motivational functions of stimuli. Journal of the Experimental Analysis of Behavior, 37, 149155.

Michael, J. (1983). Establishing operations. The Behavior Analist, 16, 191-206.

Michael, J. (2000). Implications and refinements of the establishing operation concept. Journal of Applied Behavior Analysis, 33, 401-410.

Skinner, B. F. (1953). Science and human behavior. New York: McMillan.

Skinner, B. F. (1955a). The control of human behavior. Transactions of the New York Academy of Science, 17, 547-551.

Skinner, B. F. (1955b). Freedom and the control of men. American Scholar, 25, 4765.

Skinner, B. F. (1956). A case history in scientific method. American Psychologist, 11, 221-223.

Skinner, B. F. (1957). Verbal behavior. New York: Appleton-Century-Crofts.

Skinner, B. F. (1961). The design of cultures. Daedalus, 90, 534-546.

Skinner, B. F. (1964). "Man". Proceedings of the American Philosophical Society, 108, 482-485.

Skinner, B. F. (1968a). The technology of teaching. New York: Appleton-CenturyCrofts.

Skinner, B. F. (1968b). The design of experimental communities. Em International encyclopedia of the social sciences (Vol. 16, pp. 271-275). New York: Macmillan.

Skinner, B. F. (1969). Contingencies of reinforcement: A theoretical analysis. New York: Appleton-Century-Crofts. 
Skinner, B. F. (1972). Cumulative record ( $3^{\text {rd }}$ ed.). New York: Appleton-CenturyCrofts.

Skinner, B. F. (1974). About behaviorism. New York: Alfred Knopf.

Skinner, B. F. (1978). Reflections on behaviorism and society. Englewood Cliffs, NJ: Prentice-Hall.

Souza, D. G. (1999). O que é contingência? Em R. A. Banaco (Org.), Sobre comportamento e cognição: Aspectos teóricos, metodológicos e de formação em Análise do Comportamento e Terapia Cognitivista (pp. 82-87). Santo André, SP: Arbytes.

Todorov, J. C. (1982). Behaviorismo e análise experimental do comportamento. Cadernos de Análise do Comportamento, 3, 10-23.
Todorov, J. C. (1985). O conceito de contingência tríplice na análise do comportamento. Psicologia: Teoria e Pesquisa, 1, 75-88.

Todorov J. C. (1987). A constituição como metacontingência. Psicologia: Ciência e Profissão, 7, 9-13.

Veblen, T. (1899/1965). A teoria da classe ociosa. São Paulo: Pioneira.

Recebido: 12/03/2003

$1^{a}$ Revisão: 08/05/2003

Última Revisão: 17/06/2003

Aceite Final: 20/06/2003

Sobre os autores

João Cláudio Todorov é Professor Titular da Universidade Católica de Goiás. É Professor Aposentado e Pesquisador Associado da Universidade de Brasília.

Maísa Moreira é aluna de graduação da Universidade de Brasília. 


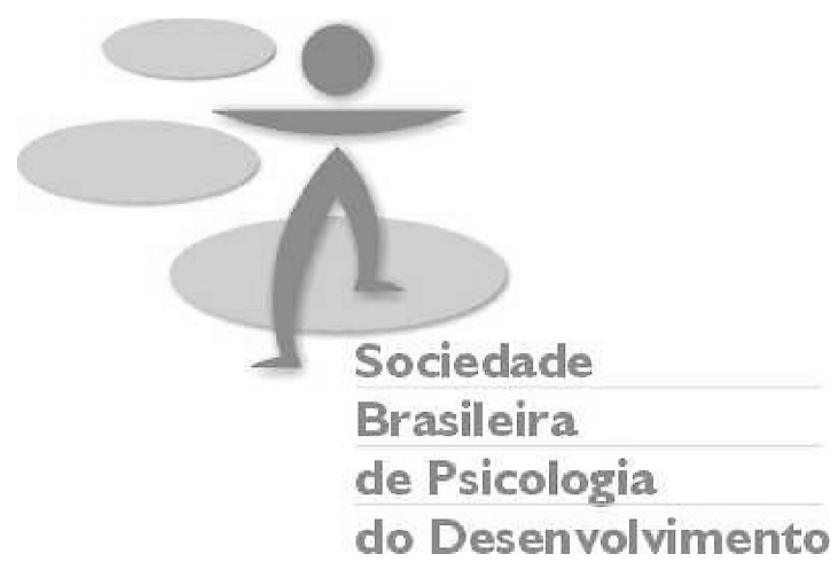

A SBPD é uma entidade de âmbito nacional, de caráter científico, que visa à divulgação e ao aprimoramento da Psicologia do Desenvolvimento, congregando psicólogos, pesquisadores, professores e estudantes de psicologia e áreas afins.

\section{Diretoria 2002/2004}

Presidente: Antonio Roazzi (UFPE)

Vice-presidente: Ana Cecília de Sousa Bastos (UFBA)

Primeira Secretária: Débora Dalbosco Dell'Aglio (UFRGS)

Segunda Secretária: Lidia Natalia Dobrianskyj Weber (UFPR)

Tesoureira: Lucia Rabello de Castro (UFRJ)

Associe-se à SBPD e você receberá os exemplares de 2004 da revista:

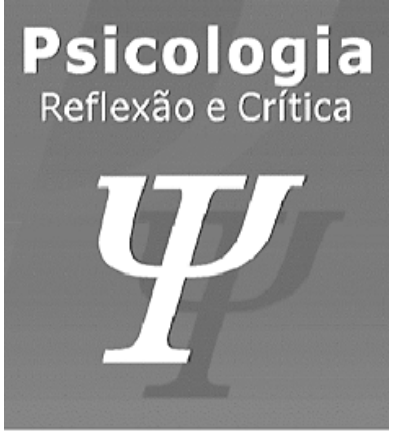

Mais informações:

Sociedade Brasileira de Psicologia do Desenvolvimento

Caixa Postal 18526

CEP 90480-970

Porto Alegre - RS

e-mail para contato: sbpd@cpovo.net

Home-page: http://www.geocities.com/sbpd_2000 